\title{
Analysis of morbidity and mortality rates in bovine in Himachal Pradesh
}

\author{
J. K Chaudhary, B. Singh, Shiv Prasad and Med Ram Verma
}

Division of Livestock Economics, Statistics and Information Technology

Indian Veterinary Research Institute, Izatnagar -243122, Bareilly, India

Corresponding author: J. K Chaudhary, email:vetjitu@gmail.com

Received: 27-01-2013, Revised: 02-03-2013, Accepted: 04-03-2013, Published online: 19-06-2013

\section{How to cite this article:}

Chaudhary JK, Singh B, Prasad S and Verma MR (2013) Analysis of morbidity and mortality rates in bovine in Himachal Pradesh, Vet World 6(9): 614-619, doi: 10.5455/vetworld.2013.614-619

\begin{abstract}
Aim: The aim of the present study was to determine the morbidity and mortality rates of Bovine population present in Himachal Pradesh, India. In addition, the effect of age, sex, environmental conditions, management practices and other factors on the morbidity and mortality rate was also analyzed using suitable statistical techniques.
\end{abstract}

Materials and Methods: Himachal Pradesh has been divided into four agro-climatic zones. Taking each agroclimatic zone as stratum, five veterinary hospitals from zone 1, two veterinary hospitals each from zone 2 and zone 3 and three veterinary hospitals from zone 4, were selected randomly. Three villages were selected from the villages covered by each veterinary hospital by simple random sampling without replacement scheme. A total of 15 livestock owners were selected from each selected village and thus a total 540 livestock owners constitute the ultimate sample from thirty six villages and twelve veterinary hospitals for the study. The sampling scheme followed in the present study is Stratified three-stage random sampling. Age, sex, season and cause wise morbidity and mortality data were collected from all selected bovine owners in the state for period of one year (January 2011 to December 2011).

Results: The Overall analysis of morbidity rate in bovine was $31.22 \%$. Among the three age groups, adults' bovine showed highest morbidity rate $35.73 \%$, followed by calves $26.98 \%$ and young stocks $23.17 \%$. Among the three age groups, calves had highest morbidity rate $16.09 \%$ due to poor management problems followed by adults $12.15 \%$ cases of reproductive problems. The overall mortality rate in bovine was found $9.14 \%$. The overall analysis of mortality in bovine with respect to age revealed significance $(\mathrm{p}<0.01)$ difference between age and sex. Amongst the three age groups, calves showed highest mortality $21.53 \%$ followed by young stocks $9.35 \%$ and adults $4.73 \%$. Among the three age groups, calves had highest mortality (16.09\%) due to poor management problems followed by $2.48 \%$ cases of digestive diseases.

Conclusion: Overall bovine morbidity and mortality rate were $31.22 \%$ and $9.14 \%$. Major causes of morbidity were reproductive diseases followed by specific diseases and mortality were poor management problems followed by digestive diseases and specific diseases.

Keywords: chi-square, digestive disorder, morbidity rate, mortality rate, reproductive diseases

\section{I ntroduction}

The success of livestock industry depends on the health of the livestock. Good health increases the productivity and any compromise on health ground shatter the hope of livestock sector. It also plays important role in the rural economy of a country as supplementing family incomes and generating gainful employment in the rural sector, particularly among the landless laborers, small and marginal farmers and women.

Total bovine population of Himachal Pradesh was 3.03 million in the year 2007 (18th livestock census) which was approx. $1 \%$ of India's bovine population (304.42 million) [1]. India is highest milk producer in

This article is an open access article licensed under the terms of the Creative Commons Attribution License (http://creativecommons. org/licenses/by/2.0) which permits unrestricted use, distribution and reproduction in any medium, provided the work is properly cited. the world (121.85 million tons of milk, 2010-11) out of which bovine milk production was-117.253 million tons) [1]. Himachal Pradesh contributes 0.90\% (1.053 million tons) of bovine milk of India [1]. Total meat production of India was 4.87 million during 2010-11 (cattle-0.81 million and buffalo- 0.211 million of meat) but Himachal Pradesh has no record of cattle and buffalo (Bovine) meat production [1]. Contribution of livestock in total GDP is $3.37 \%$, Livestock in agricultural GDP is $27.28 \%$ and agriculture in total GDPis $12.34 \%$ [1].

The knowledge of occurrence and pattern of animal diseases becomes vital in the management, as the main objective of the good management is to reduce the disease incidence and increase the productivities and reproduction. Estimation of morbidity and mortality rate in the population is an important tool for determining the disease status. In the present study the 
Table-1. Morbidity rate in bovine

\begin{tabular}{|c|c|c|c|c|c|}
\hline \multirow[t]{2}{*}{ Disease } & \multicolumn{2}{|c|}{ Cattle } & \multicolumn{2}{|c|}{ B uffalo } & \multirow[t]{2}{*}{ Bovine \% } \\
\hline & Diseased & $\%$ & Diseased & $\%$ & \\
\hline Reproductive diseases & 119 & 8.20 & 45 & 9.66 & 8.93 \\
\hline Specific diseases & 98 & 6.75 & 22 & 4.72 & 5.74 \\
\hline Parasitic diseases & 92 & 6.34 & 16 & 3.43 & 4.89 \\
\hline Digestive diseases & 73 & 5.03 & 20 & 4.29 & 4.66 \\
\hline Injury and accidents & 23 & 1.58 & 2 & 0.43 & 1.005 \\
\hline $\begin{array}{l}\text { Nutritional deficiency, } \\
\text { respiratory diseases and poisoning }\end{array}$ & 30 & 2.07 & 7 & 1.50 & 1.79 \\
\hline Others & 48 & 3.31 & 24 & 5.15 & 4.23 \\
\hline Total & 483 & 33.26 & 136 & 29.18 & 31.22 \\
\hline Total no. available & 1452 & & 466 & & \\
\hline
\end{tabular}

Table-1.1. Age wise morbidity rate in bovine

\begin{tabular}{|c|c|c|c|c|c|c|c|}
\hline \multirow[t]{2}{*}{ Disease } & \multicolumn{2}{|c|}{ Calf } & \multicolumn{2}{|c|}{ Young stocks } & \multicolumn{2}{|c|}{ Adults } & \multirow[t]{2}{*}{$\chi^{2}$ cal } \\
\hline & No. & $\%$ & No. & $\%$ & No. & $\%$ & \\
\hline Specific diseases & 7 & 1.73 & 5 & 2.03 & 108 & 8.52 & $32.63^{* *}$ \\
\hline Reproductive diseases & 1 & 0.25 & 9 & 3.66 & 154 & 12.15 & $64.1^{\star *}$ \\
\hline Parasitic diseases & 15 & 3.71 & 19 & 7.72 & 74 & 5.84 & 4.93 \\
\hline Digestive diseases & 16 & 3.96 & 13 & 5.28 & 64 & 5.05 & 0.90 \\
\hline Injury and accidents & 2 & 0.50 & 3 & 1.22 & 20 & 1.58 & 2.81 \\
\hline $\begin{array}{l}\text { Nutritional deficiency, respiratory } \\
\text { diseases and poisoning }\end{array}$ & 3 & 0.74 & 1 & 0.41 & 33 & 2.60 & $9.06^{*}$ \\
\hline Others & 65 & 16.09 & 7 & 2.85 & 0 & 0.00 & $27.23^{\star *}$ \\
\hline Total & 109 & 26.98 & 57 & 23.17 & 453 & 35.73 & $21.42^{* *}$ \\
\hline Total no. available & 404 & & 246 & & 1268 & & \\
\hline
\end{tabular}

bovine morbidity and mortality rate in Himachal Pradesh were determined and role of host, agent and environmental factors influencing these rate were also identified.

\section{Materials and Methods}

Sampling design: Himachal Pradesh state of India has twelve districts that were divided into four agroclimatic zones. Zone 1 comprises of five districts, zone 2 and zone 3 each comprises of two districts and zone four comprises of three districts [2]. By taking four agro-climatic zones as strata, five veterinary hospitals from zone 1 , two veterinary hospitals each from zone 2 and zone 3 and three veterinary hospitals from zone 4, were selected randomly [3]. Three villages were selected from the villages covered by each veterinary hospital by simple random sampling without replacement scheme.

A total of 15 livestock owners were selected from each selected village and thus a total 540 livestock owners constitute the ultimate sample from 36 villages

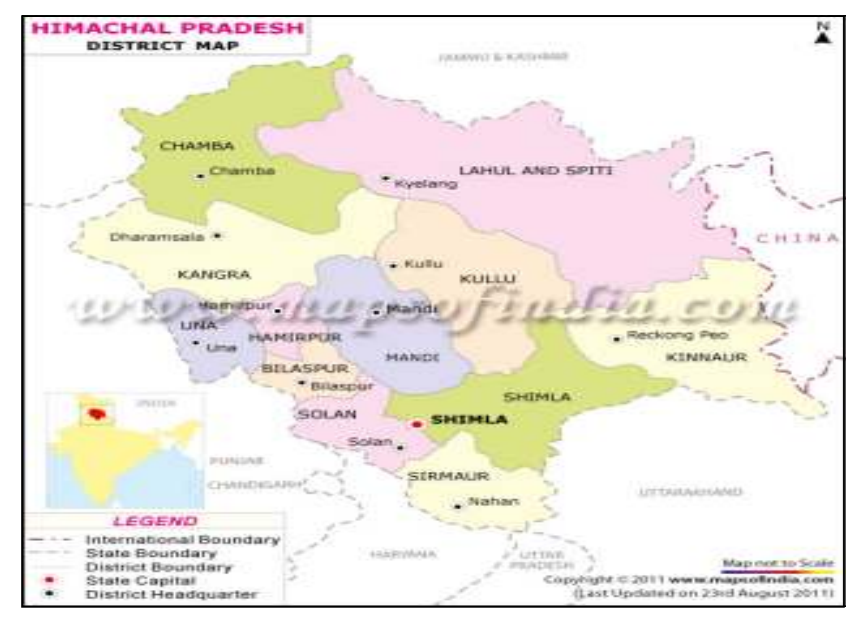

and twelve veterinary hospitals for the study. The sampling scheme followed in the present study was the Stratified three-stage random sampling [4, 5]. Age, sex, season and cause wise morbidity and mortality data were collected from all selected bovine owners in the state for period of one year (January 2011 to December 2011). The diseases observed during the study period were classified 1) Digestive diseases, 2) Respiratory diseases, 3) Reproductive problems, 4) Parasitic diseases, 5) Specific diseases, (FMD, Mastitis, HS, Enzootic bovine haematuria, Rabies, Actinomycosis), 6) Nutritional and metabolic diseases, 7) Injuries and accidents, 8) Other Diseases (due to poor management problems) [6].

\section{Methodology:}

Morbidity/ mortality rate: The the morbidity/mortality rate resulting from various diseases was calculated by the formula:

Number of cases (deaths) observed during period/ Population (mid-year) $\times 100$

Association between cattle morbidity and mortality rate and different factors was calculated by $\chi 2$ test.

Chi-square analysis: This test is suitable for analyzing the categorical data. It compares the observed frequencies with expected frequencies under null hypothesis. Test statistic is based on counts that represent the number of items falling in each category. It is used for testing significance of patterns in qualitative data. Test statistics measures the agreement between actual counts and expected counts assuming the null hypothesis. The chi-square distribution can be used to see whether or not the observed counts agree with an expected counts [7].

The chi-square analysis done by using following 
Table-1.2. Sex wise morbidity rate in bovine

\begin{tabular}{|c|c|c|c|c|c|}
\hline \multirow[t]{2}{*}{ Disease } & \multicolumn{2}{|c|}{ Male } & \multicolumn{2}{|c|}{ Female } & \multirow[t]{2}{*}{$\chi^{2}$ cal } \\
\hline & No. & $\%$ & No. & $\%$ & \\
\hline Specific diseases & 2 & 0.41 & 118 & 8.22 & $37.57^{\star \star}$ \\
\hline Reproductive diseases & 0 & 0 & 163 & 11.36 & Not calculated \\
\hline Parasitic diseases & 30 & 6.21 & 78 & 5.44 & 0.41 \\
\hline Digestive diseases & 14 & 2.90 & 79 & 5.51 & $5.32^{*}$ \\
\hline Injury and accidents & 5 & 1.04 & 20 & 1.39 & 0.36 \\
\hline $\begin{array}{l}\text { Nutritional deficiency, respiratory } \\
\text { diseases and poisoning }\end{array}$ & 12 & 2.48 & 25 & 1.74 & 1.05 \\
\hline Others & 72 & 14.91 & 0 & 0.00 & $\mathrm{NC}$ \\
\hline Total & 136 & 28.16 & 483 & 33.66 & $5.0^{*}$ \\
\hline Total no. available & 483 & & 1435 & & \\
\hline
\end{tabular}

Table-1.3. Feeding management factor (Grazing) wise morbidity rate in bovine

\begin{tabular}{|c|c|c|c|c|c|}
\hline \multirow[t]{2}{*}{ Disease } & \multicolumn{2}{|c|}{ Yes } & \multicolumn{2}{|c|}{ No } & \multirow[t]{2}{*}{$\chi^{2}$ cal } \\
\hline & No. & $\%$ & No. & $\%$ & \\
\hline Specific diseases & 57 & 5.76 & 63 & 6.78 & 0.85 \\
\hline Reproductive diseases & 71 & 7.18 & 93 & 10.01 & $4.91^{*}$ \\
\hline Parasitic diseases & 67 & 6.77 & 41 & 4.41 & $5.03^{*}$ \\
\hline Digestive diseases & 43 & 4.35 & 50 & 5.38 & 1.11 \\
\hline Injury and accidents & 20 & 2.02 & 5 & 0.54 & $8.20^{* \star}$ \\
\hline $\begin{array}{l}\text { Nutritional deficiency, respiratory } \\
\text { diseases and poisoning }\end{array}$ & 14 & 1.42 & 23 & 2.48 & 2.85 \\
\hline Others & 25 & 2.53 & 47 & 5.06 & $8.50^{\star *}$ \\
\hline Total & 297 & 30.03 & 322 & 34.66 & $4.7^{*}$ \\
\hline Total no. available & 989 & & 929 & & \\
\hline
\end{tabular}

formula;

$$
\chi^{2}=\sum \frac{(\mathrm{O}-\mathrm{E})^{2}}{\mathrm{E}}
$$

$\mathrm{O}=$ Observed count and $\mathrm{E}=$ Expected count

Statistical analysis: The data were compiled and statistical SPSS program version 17 [3] was used to compare the result [8].

\section{Results and Discussion}

A total of 1918 livestock of different age and breeds were maintained by 540 livestock owners selected for the study during period of $1^{\text {st }}$ January 2011 to $31^{\text {st }}$ December 2011.

The reproductive diseases were more prominent having highest morbidity rate $8.93 \%$, followed by specific diseases $5.74 \%$, parasitic diseases $4.89 \%$, digestive diseases $4.66 \%$, injury and accidents $1.0 \%$, diseases (nutritional deficiency, respiratory diseases and poisoning) $1.79 \%$ and poor management problems $4.23 \%$. (Table- 1 )

The morbidity data was categorized according to age as, calf (0-1years), young stocks (1-3 years) and adults (more than three years) in bovine. Amongst the three age groups, adults bovine showed highest morbidity rate (35.73\%), followed by calves (26.98\%) and young stocks $(23.17 \%)$. Among the three groups, calves had highest morbidity rate due to poor management problems $(16.09 \%)$ followed by adults $(12.15 \%)$ cases of reproductive problems. Calves were having low immunity and proper feeding and management was not provided to them during their early days of life $[9,10]$. The chi-square analysis revealed that there was significant difference $(p<0.01)$ between age groups in bovine (Table-1.1).

Effect of sex on morbidity rate revealed that in case of male bovine, poor management cases showed high morbidity rate $(14.91 \%)$, while in female bovine, morbidity rate was high due to reproductive disorders $(11.36 \%)$ [11,12]. Parasitic diseases were more in male $(6.21 \%)$ than female $(5.44 \%)$. The chi-square analysis showed that the morbidity rates differ significantly $(\mathrm{p}<0.01)$ between male and female [13] (Table-1.2).

The analysis of morbidity of data according to grazing and non- grazing revealed that in non-grazing group the reproductive disorders $(10.01 \%)$, specific diseases $(6.78 \%)$ and poor management cases $(5.06 \%)$ were more than grazing group in bovine. The chisquare analysis revealed that there was significant difference $(p<0.05)$ in morbidity rate between grazing and non-grazing group in bovine (Table-1.3) [14-16].

Study of mortality rate revealed that majority of deaths occurred in bovine during study period were maximum due to poor management problems $4.23 \%$ followed by digestive diseases $1.65 \%$ and specific diseases $0.92 \%$. The overall analysis of mortality rate in bovine with respect to age revealed significance $(p<0.01)$ difference between age and sex group. Amongst the three age groups, calves showed highest mortality $(21.53 \%)$ followed by young stocks $(9.35 \%)$ and adults $(4.73 \%)$. Among the three groups, calves had highest $(16.09 \%)$ mortality rate due to poor management cases followed by $2.48 \%$ cases of digestive diseases. Calves were having low immunity and proper feeding and management was not provided to them during their early days of life. The mortality rate decreases with increase in age. This may due to the reason that calves were having low immunity and proper feeding and management was not provided to them during their early days of life [17-21] (Table-2.1).

The overall analysis of mortality rate in bovine with respect to sex revealed significance $(p<0.01)$ 
Table-2. Mortality rate in bovine

\begin{tabular}{|c|c|c|c|c|c|}
\hline \multirow[t]{2}{*}{ Disease } & \multicolumn{2}{|c|}{ Cattle } & \multicolumn{2}{|c|}{ Buffalo } & \multirow[t]{2}{*}{ Bovine \% } \\
\hline & Died & $\%$ & Died & $\%$ & \\
\hline Digestive diseases & 26 & 1.79 & 7 & 1.50 & 1.645 \\
\hline Specific diseases & 8 & 0.55 & 6 & 1.29 & 0.92 \\
\hline Injury and accidents & 19 & 1.31 & 1 & 0.21 & 0.76 \\
\hline Poisoning & 8 & 0.55 & 4 & 0.86 & 0.705 \\
\hline Parasitic diseases & 6 & 0.41 & 1 & 0.21 & 0.31 \\
\hline $\begin{array}{l}\text { Nutritional, respiratory and } \\
\text { reproductive disorders }\end{array}$ & 10 & 0.69 & 2 & 0.43 & 0.56 \\
\hline Others & 48 & 3.31 & 24 & 5.15 & 4.23 \\
\hline Total & 125 & 8.61 & 45 & 9.66 & 9.135 \\
\hline Total no. available & 1452 & & 466 & & \\
\hline
\end{tabular}

Table-2.1. Age wise mortality rate in bovine

\begin{tabular}{|c|c|c|c|c|c|c|c|}
\hline \multirow[t]{2}{*}{ Disease } & \multicolumn{2}{|c|}{ Calf } & \multicolumn{2}{|c|}{ Young stocks } & \multicolumn{2}{|c|}{ Adults } & \multirow[t]{2}{*}{$\chi^{2}$ cal } \\
\hline & No. & $\%$ & No. & $\%$ & No. & $\%$ & \\
\hline Specific diseases & 6 & 1.49 & 1 & 0.41 & 7 & 0.55 & 4.09 \\
\hline Digestive diseases & 10 & 2.48 & 8 & 3.25 & 15 & 1.18 & $6.94^{*}$ \\
\hline Injury and accidents & 2 & 0.50 & 3 & 1.22 & 15 & 1.18 & 1.49 \\
\hline Parasitic diseases & 3 & 0.74 & 2 & 0.81 & 2 & 0.16 & 4.44 \\
\hline Poisoning & 1 & 0.25 & 0 & 0.00 & 11 & 0.87 & 1.65 \\
\hline $\begin{array}{l}\text { Nutritional, respiratory and } \\
\text { reproductive disorders }\end{array}$ & 0 & 0.00 & 2 & 0.81 & 10 & 0.79 & 0.002 \\
\hline Others & 65 & 16.09 & 7 & 2.85 & 0 & 0.00 & $27.23^{\star *}$ \\
\hline Total & 87 & 21.53 & 23 & 9.35 & 60 & 4.73 & $107.17^{* *}$ \\
\hline Total no. available & 404 & & 246 & & 1268 & & \\
\hline
\end{tabular}

Table-2.2. Sex wise mortality rate in bovine

\begin{tabular}{|c|c|c|c|c|c|}
\hline \multirow[t]{2}{*}{ Disease } & \multicolumn{2}{|c|}{ Male } & \multicolumn{2}{|c|}{ Female } & \multirow[t]{2}{*}{$\chi^{2}$ cal } \\
\hline & No. & $\%$ & No. & $\%$ & \\
\hline Specific diseases & 0 & 0.00 & 14 & 0.98 & NC \\
\hline Digestive diseases & 11 & 2.28 & 22 & 1.53 & $6.34^{*}$ \\
\hline Injury and accidents & 5 & 1.04 & 15 & 1.05 & 0.0 \\
\hline Parasitic diseases & 2 & 0.41 & 5 & 0.35 & 0.04 \\
\hline Poisoning & 7 & 1.45 & 5 & 0.35 & $7.04^{* *}$ \\
\hline $\begin{array}{l}\text { Nutritional, respiratory and } \\
\text { reproductive disorders }\end{array}$ & 4 & 0.83 & 8 & 0.56 & 0.43 \\
\hline Others & 72 & 14.91 & 0 & 0.00 & $\mathrm{NC}$ \\
\hline Total & 101 & 20.91 & 69 & 4.81 & $116.00^{\star *}$ \\
\hline Total no. available & 483 & & 1435 & & \\
\hline
\end{tabular}

Table-2.3. Feeding management factor (Grazing) wise mortality rate in bovine

\begin{tabular}{|c|c|c|c|c|c|}
\hline \multirow[t]{2}{*}{ Disease } & \multicolumn{2}{|c|}{ Yes } & \multicolumn{2}{|c|}{ No } & \multirow[t]{2}{*}{$\chi^{2}$ cal } \\
\hline & No. & $\%$ & No. & $\%$ & \\
\hline Specific diseases & 7 & 0.71 & 7 & 0.75 & 0.014 \\
\hline Digestive diseases & 17 & 1.72 & 16 & 1.72 & 0.0 \\
\hline Injury and accidents & 15 & 1.52 & 5 & 0.54 & $4.45^{*}$ \\
\hline Parasitic diseases & 1 & 0.10 & 6 & 0.65 & $3.91^{*}$ \\
\hline Poisoning & 4 & 0.40 & 8 & 0.86 & 1.61 \\
\hline $\begin{array}{l}\text { Nutritional, respiratory and } \\
\text { reproductive disorders }\end{array}$ & 6 & 0.61 & 6 & 0.65 & 0.012 \\
\hline Others & 25 & 2.53 & 47 & 5.06 & $8.50^{* *}$ \\
\hline Total & 75 & 7.58 & 95 & 10.23 & $4.14^{\star}$ \\
\hline Total no. available & 989 & & 929 & & \\
\hline
\end{tabular}

difference between sex. Male bovine showed maximum $(20.91 \%)$ mortality than female mortality $(4.81 \%)$. The reason for this may be given the fact that more care is given to female bovine due to their economic importance as compared to their male counterparts (Table- 2.2).

Significant $(p<0.05)$ difference was found in the overall analysis of mortality in bovine with respect to grazing and non-grazing habit. High mortality $(10.23 \%)$ had showed by non-grazing bovine than grazing bovine ( $7.58 \%$ ) (Table-2.3).

Reproductive diseases are major problem that affecting bovine under village condition though they are recorded only in female. Relative to other diseases the incidence rate of reproductive disease was more. The reason for this is silent heat, in local or desi bovine/cross bred bovine which farmer did not able to detect, the nutritional status under village condition is poor in minerals which leads to irregular estrous of female, further hormonal imbalance leads to repeat breeding which is supposed to be the major reason for reproductive diseases. The main cause of repeat was faulty AI (artificial insemination), infections of genital organs due to improper hygiene [22,23]. 
The morbidity and mortality rates due to various infectious diseases were found to be high. The inadequate knowledge about deworming, vaccination, lack of knowledge about importance of proper ventilation, reluctance of farmers of getting deworming and vaccination done in their livestock etc. were major problems that lead to recurrent outbreaks of infectious diseases.

Occurrences of digestive diseases were high in village condition which may relate to the feeding management of bovine. Lack of knowledge regarding balance feeding among villager leads to various digestive diseases conditions. Animals are fed on low cost and low nutrient diet; sudden changes in feeding of animals are the factors which supplement the disease occurrence $[24,25]$.

\section{Conclusions}

Overall morbidity and mortality rate were $31.22 \%$ and $9.14 \%$ in bovine population respectively. Major causes of morbidity were reproductive diseases followed by specific diseases and mortality were poor management problems followed by digestive and specific diseases. Adult bovine showed high morbidity due to reproductive problems which are major challenges under village conditions in study area. Major emphases are laid to attend reproductive problems. The female were at higher risk of morbidity but males were at higher risk of mortality in bovine. Logistic regression analysis showed that grazing reduces risk of morbidity as high morbidity rate recorded in non-grazing bovine. The calves were found at more risk of mortality. The probability getting disease reduces with increase in age. Mortality rate was high in bovine calves due to poor management. Logistic regression analysis showed that the male were at higher risk of mortality as compared to female.

\section{Authors' contributions}

JKC and BS designed the study. JKC conducted the study and analysed the data. SP and MRV drafted and revised the manuscript. All authors read and approved the final manuscript.

\section{Acknowledgements}

The authors are thankful to Indian Council of Agricultutal Research (ICAR) for providing Junior Research Fellowship (JRF) during research work. Authors are also thankful to all field veterinarians who helped in collection of data from all parts of Himachal Pradesh, without which completion of this work would have not been possible.

\section{Competing interests}

The authors declare that they have no competing interests.

\section{References}

1. BAHS (2012) 18th Live Stock Census, Department of Animal Husbandry, Dairying and Fisheries, Ministry of Agriculture available on http://dahd.nic.in. (Retrieval date-
11/01/2013).

2. Ahluwalia, M.S. (1998) Social, Cultural and Economic History of Himachal Pradesh. Indus Publishing. ISBN 8173870896.

3. Department of Animal Husbandry, Himachal Pradesh, 2011(Retrieval date-10/05/2012).

4. Cochran, W.G. (1961) Comparison of methods for determining strata boundaries, Bull. Int. Stat. Inst., 38 (Part II), 345-58.

5. Cochran, W.G. (1977) Sampling Techniques, $3^{\text {rd }}$ edition, 65110, Wiley Eastern, New Delhi.

6. Prasad, S., Ramachandran, N. and Raju, S. (2004) Mortality patterns in dairy animals under organised herd management conditions at Karnal, India. Trop. Anim. Health Prod., 36: 645-654.

7. Gupta, S.C. and Kapoor, V.K., (2010) Fundamental of Mathematical statistics, Sultan Chand and Sons, New Delhi, $11^{\text {th }}$ edition, $15.1-15.56$.

8. SPSS/PC, Windows for version-17.0. Release on December 2008 (Microsoft Corp).

9. Sundaram. S. (2010) Estimation and analysis of morbidity pattern in cattle in Cauvery delta Region of Tamilnadu. M.V.Sc. Thesis, Indian Veterinary Research Institute, Deemed University.

10. Palanivel, K.M., Vijayalingam, T.A., Selvasubramanian, S. and Mohanraj, M. (2007) A retrospective study on calf morbidity and mortality pattern in Tamil Nadu. Indian $J$. Field Vet., 3(1): 41-43.

11. Meena H. R., Ram Hira, Sahoo.A. and Rasool T. J. (2008) Livestock husbandry Scenario at high altitude Kumaon Himalaya. Ind. J. Anim. Sci., 78(8): 882-886.

12. Shaikh, S.R (2009) Estimation and analysis of morbidity and mortality pattern in cattle under village conditions of Maharashtra. M.V.Sc. Thesis, Indian Veterinary Research Institute, Deemed University.

13. Khalate, N. (2009) Logistic regression analysis of morbidity and mortality in organised farms of Maharashtra. M.V.Sc. Thesis submitted to Indian Veterinary Research Institute, Izatnagar, and Uttar Pradesh.

14. Dana, S.S., Rathore, B.S. and Kaul,P. N. (2001) Morbidity and mortality pattern in desi cattle reared by the Santal tribe of West Bengal. Indian Journal of Animal Research, 35(1): 47-49.

15. Bilal, M.Q., Hameed, A. and Ahmad, T. (2009) Prevalence of gastrointestinal parasites in buffalo and cow calves in rural areas of Toba Tek Singh, Pakistan JAPS, Journal of Animal and Plant Sciences, 19(2): 67-70.

16. Singh, Rajeev, Hari, Shankar, Arora, B.M. and Singh, V.P. (2005) Studies on morbidity and mortality pattern in cattle at the organized farms of different Agro-geo-climatic conditions in Uttar Pradesh. Indian Journal of Animal Health, 44(1): 47-53.

17. Wudu, T., Kelay, B., Mekonnen, H.M. and Tesfu, K. (2008) Calf morbidity and mortality in smallholder dairy farmsin Ada'a Liben district of Oromia, Ethiopia. Tropical Animal Health and Production, 40:369-376.

18. Zaman, T., Khan, A. and Akhtar, M.Z. (2006) Some of the risk factors of Nili-Ravi buffalo (Bubals bubalis) neonatal calf mortality in Pakistan. Pakistan Vet. J. 121-125.

19. Singh, Rajeev (2000) Epidemiological studies on mortality patterns in selected organized farms of Uttar Pradesh. M.V.Sc. Thesis submitted to Indian Veterinary Research Institute, Izatnagar, and Uttar Pradesh.

20. Kumar, C.R., Moorthy, P.R.S., Rao, K.S. and Naidu, K.V. (2002) Calf mortality pattern in relation to age and sex in organized livestock farms in Andhra Pradesh. Indian Journal of Animal Sciences, 72(10): 921-923.

21. Khan, A., Saddique, U., Ahmad, R., Khan, H., Mohammad. Y., and Zubair M. (2006) Serosurveillance of hemorrhagic septicemia in cattle and buffaloes in district malakand, NWFP Journal of Agricultural and Biological Science, 1:4.

22. Nilesh (2009) Logistic regression analysis of Morbidity and 
Mortality in organised farms of Maharashtra. M.V.Sc. thesis. Indian Veterinary Research Institute, Deemed University.

23. Singh, B. P., Sharma, M. C. and Tiwari, R. (2009) Effect of Foot and Mouth Disease (FMD) vaccination in linkage villages of IVRI's India. Livestock Res. Rural Develop., 19:119.
24. Singh, B. and Prasad Shiv (2008) Economic evaluation of important cattle diseases in India. Indian Vet. J., 85(11): 1207-1210.

25. Singh, B. and Prasad, S. (2009) A model based assessment of economic losses due to some important diseases in sheep in India. Indian J. Ani. Sci., 79(12): 1265-1268.

$* * * * * * * *$ 